\title{
QUALIDADE FISIOLÓGICADE SEMENTES DE FEIJÃO CAUPI EM QUATRO REGIÕES DO ESTADO DO CEARÁ ${ }^{1}$
}

\author{
ALEK SANDRO DUTRA² ${ }^{2}$ ELIZITAMARIATEÓFILO ${ }^{3}$, SEBASTIÃO MEDEIROS FILHO ${ }^{4}$, FRANCISCO TIAGO CUNHADIAS ${ }^{5}$
}

\begin{abstract}
RESUMO - O presente trabalho foi realizado com o objetivo de avaliar a qualidade fisiológica das sementes de feijão caupi, colhidas em quatro regiões do Estado do Ceará. Foram utilizadas sementes das cultivares Sempre verde, Setentão, Patativa, Pingo de ouro, Aparecido e Epace-10. Essas sementes foram produzidas nos municípios cearenses de Quixadá, Pentecoste, Limoeiro do Norte e Morada Nova, durante o ano de 2004. Foram realizados os teste de germinação, primeira contagem de germinação, emergência de plântulas, índice de velocidade de emergência e de condutividade elétrica. Para a maioria das cultivares testadas, as sementes produzidas em Pentecoste e Limoeiro do Norte apresentaram qualidade fisiológica superior quando comparada com aquelas produzidas em Quixadá e Morada Nova; As sementes das cultivares Sempre Verde, Setentão, Pingo de Ouro e Aparecido obtiveram desempenho superior, as da cultivar Epace-10 desempenho intermediário e as da Patativa, desempenho inferior.
\end{abstract}

Termos para indexação: Vigna unguiculata, germinação, vigor, cultivares

\section{PHYSIOLOGICAL QUALITY OF COWPEA SEEDS IN FOUR REGIONS OF THE STATE OF CEARÁ}

\begin{abstract}
The present study aimed to evaluate the physiological quality of cowpea seeds from the cultivars Sempre verde, Setentão, Patativa, Pingo de ouro, Aparecido and Epace-10 collected in four different regions of the State of Ceará. The seeds were produced in Quixadá, Pentecoste, Limoeiro do Norte and Morada Nova Counties during 2004. The seeds were tested for germination, first germination counting, seedling emergence, emergence speed index, and electric conductivity. The physiological quality of the seeds produced in Pentecoste and Limoeiro do Norte counties was better than the physiological quality of those produced in Quixadá and Morada Nova, for the majority of the cultivars tested. The seeds of the cultivars Sempre Verde, Setentão, Pingo de Ouro and Aparecido showed superior performance, the cultivar Epace-10 showed intermediary performance and the cultivar Patativa showed inferior performance.
\end{abstract}

Index terms: Vigna unguiculata, germination, vigour, cultivars

\section{INTRODUÇÃO}

O cultivo do feijão caupi (Vigna unguiculata (L.) Walp) é uma atividade de grande importância para o desenvolvimento agrícola da região Nordeste, tanto no aspecto econômico como no nutricional, pois é o alimento básico na alimentação das populações mais pobres, exercendo função social no suprimento das necessidades nutricionais dessa camada

\footnotetext{
${ }^{1}$ Submetido em 08/09/2005. Aceito para publicação em 13/02/2007.

2 Eng $^{\circ}$. Agrônomo, Dr., UFC, Depto. de Fitotecnia, CaixaPostal 12.168, 60.356-001, Fortaleza,CE, Bolsista CNPq/DCR, alekdutra@bol.com.br
}

da população.

Independentemente da escolha de regiões favoráveis à produção de sementes, do controle do ambiente no armazenamento ou dos arranjos de práticas culturais aplicadas à melhoria de sua qualidade, o fator determinante e fundamental de qualidade fisiológica é intrínseco e depende do controle genético dessa característica pela cultivar (Krzyzanowski et al., 1993). Damião Filho e Moro (2001), relatam que a

\footnotetext{
${ }^{3}$ Eng ${ }^{\mathrm{a}}$. Agrônoma, Dra. UFC, Depto de Fitotecnia, Fortaleza-CE, elizita@ufc.br

${ }^{4}$ Prof. Dr., Depto de Fitotecnia/UFC, Fortaleza-CE, Bolsista do CNPq, filho@ufc.br.

${ }^{5}$ Aluno do Curso de graduação em Agronoma do CCA/UFC
} 
produção agrícola nunca é superior à capacidade da semente utilizada, ou seja, nenhum trato cultural pode melhorar a produção além dos limites genéticos impostos pelo embrião da semente. É essencial para o aumento da produtividade, a melhoria do nível tecnológico do feijoeiro, na qual inclui-se o emprego de sementes de alta qualidade (Bragantini, 1996; Yokoyama et al., 2000). A qualidade de sementes pode ser verificada pela interação de quatro fatores: genético, físico, sanitário e fisiológico (Ambrosano et al., 1999). Para Vieira et al. (1993), o componente fisiológico pode ser influenciado pelo ambiente em que as sementes se formam.

Segundo Krzyzanowski et al. (1993), a utilização de sementes de boa qualidade fisiológica é fator primordial no estabelecimento de qualquer lavoura. Sementes de baixa qualidade, isto é, com potencial de germinação e vigor reduzidos, originam lavouras com baixa população de plantas e em conseqüência disto acarreta sérios prejuízos econômicos (Krzyzanowski et al., 1993).

O presente trabalho foi realizado com o objetivo de avaliar a qualidade fisiológica das sementes de feijão caupi, colhidas em quatro regiões do Estado do Ceará.

\section{MATERIALE MÉTODOS}

A pesquisa foi desenvolvida no Laboratório de Análise de Sementes do Departamento de Fitotecnia da Universidade Federal do Ceará-UFC, Fortaleza. Foram utilizadas sementes de feijão caupi, cultivares Sempre verde, Setentão, Patativa, Pingo de ouro, Aparecido e Epace-10, todas de ciclo médio. Estas sementes foram produzidas nos municípios cearenses de Quixadá, Pentecoste, Limoeiro do Norte e Morada Nova durante o ano de 2004, em decorrência do Convênio UFC/ Centro de Ciências Agrárias/Secretaria de Agricultura e Pecuária do Estado do Ceará. As cultivares testadas foram oriundas do Banco de Germoplasma de Caupi, pertencente a UFC, selecionadas com base no potencial produtivo e adaptabilidade às condições do Estado. O delineamento utilizado nos experimentos de campo foi o de blocos casualizados, com quatro repetições. Em Quixadá, o ensaio foi conduzido na Fazenda Experimental Lavoura Seca/UFC, em Pentecoste, na Fazenda Experimental do Vale do Curu/UFC, em Limoeiro do Norte, na Chapada do Apodi área pertencente ao Centro de Tecnologia de Limoeiro do Norte e em Morada Nova no sítio Diadema.

Foram retiradas amostras de cada cultivar, por repetição de campo, as quais foram submetidas a testes de avaliação da qualidade fisiológica. Em todo o período experimental, as sementes foram mantidas em embalagens de sacos plásticos e armazenados em câmara fria e seca $\left(7^{\circ} \mathrm{C}\right.$ e $45 \%$ UR). Determinação do teor de água (base úmida): foi determinado em estufa a $105 \pm 3^{\circ} \mathrm{C}$ por $24 \mathrm{~h}$ (Brasil, 1992), utilizando-se quatro amostras de 50 sementes, para cada cultivar/local. Os resultados foram expressos em porcentagem. Teste de germinação: foram utilizadas quatro repetições de 50 sementes por cultivar/local, semeadas em rolos de papel toalha tipo Germitest, umedecidos com água o equivalente a 2,5 vezes o peso do substrato seco e colocadas para germinar a $25^{\circ} \mathrm{C}$. As avaliações foram realizadas aos quatro e sete dias após a semeadura, e os resultados expressos em porcentagem média com base no número de plântulas normais. Primeira contagem de germinação: conduzido, conjuntamente, com o teste de germinação, computando-se a porcentagem de plântulas normais, no quarto dia após a semeadura. Emergência de plântulas: para essa avaliação, quatro repetições de 50 sementes por cultivar/local foram semeadas em canteiros de $10 \times 1,0 \mathrm{~m}$, com $10 \mathrm{~cm}$ entre repetições, contendo substrato terra/areia na proporção 1:1. As irrigações foram feitas sempre que necessário, visando o fornecimento de água para a germinação das sementes e emergência das plântulas. O teste foi avaliado sete dias após a semeadura, sendo computado a porcentagem de plântulas normais. Índice de velocidade de emergência: para a determinação deste índice foram realizadas contagens diárias a partir da emergência da primeira plântula. Foram consideradas emergidas as plântulas que apresentavam cotilédones acima do solo, em posição aberta, liberando as folhas primarias. A contagem prosseguiu até à estabilização da emergência das plântulas. O índice foi calculado conforme Maguire (1962). Teste de condutividade elétrica: quatro repetições de 50 sementes foram pesadas com precisão de duas casas decimais $(0,01 \mathrm{~g})$ e colocadas para embeber em copos de plásticos (200 mL), contendo $75 \mathrm{~mL}$ de água destilada, a temperatura de $25^{\circ} \mathrm{C}$, por períodos de 24 horas. Após o período de imersão, a condutividade elétrica da solução foi medida através de leituras em um aparelho condutivimetro TECNOPON, modelo CA150, com resultados expressos em $\mathrm{mS} \mathrm{cm}^{-1} \mathrm{~g}^{-1}$. A leitura de cada repetição foi realizada logo após a retirada do material da incubadora, de modo gradativo, agitando-se, cuidadosamente, cada recipiente, com o intuito de uniformizar os eletrólitos lixiviados na solução.

Para as análises em laboratório utilizou-se o delineamento inteiramente casualizado, com quatro repetições. A comparação das médias foi realizada pelo teste de Tukey, em nível de 5\% de probabilidade (Banzatto e Kronka, 1992). 


\section{RESULTADOS E DISCUSSÃO}

Conforme dados apresentados na (Tabela 1), observouse que houve diferença entre cultivares quando as sementes foram produzidas nos ensaios instalados nos municípios de Quixadá e Morada Nova. A cultivar Patativa foi a que apresentou menor germinação, 30\% em Quixadá. Nesta localidade a cultivar Epace-10 ficou com valor intermediário e as outras cultivares apresentaram germinação superior a 85\%. Em Morada Nova, a Patativa não diferiu da Epace-10. Mesmo não havendo diferença significativa entre as cultivares produzidas nos municípios de Pentecoste e Limoeiro do Norte, verificou-se que todas tiverem percentual de germinação acima de $90 \%$. Jauer et al. (2002) trabalhando com três cultivares de feijão, observaram diferenças significativa, sendo a cultivar IAPAR 44 a que apresentou menor germinação, não diferindo da cultivar Xamego. As cultivares TPS Bionobre e TPS Nobre foram as melhores com germinação superior a $80 \%$. Costa et al. (2001) encontraram sementes de soja oriundas do sul do Paraná e do Rio Grande do Sul apresentando excelente comportamento de qualidade fisiológica, quando comparadas com as de outras regiões produtoras do Brasil. Para Santos et al. (2000), as linhagens de soja UFV 96-570876, UFV 96570818 e UFV 96-570835 se destacaram por suas sementes, produzidas em três regiões do Estado de Minas Gerais, por apresentarem nos teste de germinação e emergência das plântulas em areia, porcentagem de germinação e emergência acima de $80 \%$.

Na Tabela 2, para o teste de primeira contagem de germinação, a cultivar Patativa foi a de menor desempenho, principalmente quando produzida em Quixadá e Morada Nova. A exemplo do teste de germinação, a cultivar Epace-10 apresentou-se como intermediária em termos de qualidade fisiológica. Observou-se que as outras cultivares foram consideradas vigorosas, com percentual de vigor acima de $80 \%$. Souza et al. (2004) verificaram que independentemente dos horários de colheita, sementes de algodão herbáceo, cultivar CNPA 7H produzidas em Tacima, microrregião do Estado da Paraíba, obtiveram melhor qualidade fisiológica em relação àquelas produzidas em Guarabira e Diamente, também, microrregião do Estado da Paraíba.

Os resultados do teste de emergência de plântulas de seis cultivares de feijão caupi colhidas em quatro localidades (Tabela 3), evidenciaram a menor qualidade da cultivar

TABELA 1. Valores médios do teste de germinação de seis cultivares de feijão caupi colhidas em quatro localidades do Estado do Ceará, Fortaleza, 2005ํ․

\begin{tabular}{lcccc}
\hline \multirow{2}{*}{ Cultivares } & \multicolumn{4}{c}{ Locais } \\
\cline { 2 - 5 } & Quixadá & Pentecoste & Limoeiro & Morada Nova \\
\cline { 2 - 5 } & $92 \mathrm{a}$ & $98 \mathrm{a}$ & $94 \mathrm{a}$ & $93 \mathrm{a}$ \\
Sempre verde & $86 \mathrm{ab}$ & $96 \mathrm{a}$ & $98 \mathrm{a}$ & $87 \mathrm{ab}$ \\
Setentão & $30 \mathrm{c}$ & $94 \mathrm{a}$ & $92 \mathrm{a}$ & $77 \mathrm{~b}$ \\
Patativa & $96 \mathrm{a}$ & $96 \mathrm{a}$ & $97 \mathrm{a}$ & $86 \mathrm{ab}$ \\
Pingo de ouro & $95 \mathrm{a}$ & $98 \mathrm{a}$ & $91 \mathrm{a}$ & $94 \mathrm{a}$ \\
Aparecido & $79 \mathrm{~b}$ & $96 \mathrm{a}$ & $95 \mathrm{a}$ & $78 \mathrm{~b}$ \\
Epace-10 & 5,97 & 4,50 & 3,71 & 7,29 \\
\hline $\mathrm{CV}(\%)$ & & &
\end{tabular}

${ }^{1}$ As médias seguidas pela mesma letra, na coluna, não diferem entre si pelo teste de Tukey a 5\% de probabilidade de erro.

TABELA2. Valores médios do teste de primeira contagem de germinação de seis cultivares de feijão caupi colhidas em quatro localidades do Estado do Ceará, Fortaleza, 2005․․

\begin{tabular}{|c|c|c|c|c|}
\hline \multirow{3}{*}{ Cultivares } & \multicolumn{4}{|c|}{ Locais } \\
\hline & Quixadá & Pentecoste & Limoeiro & Morada Nova \\
\hline & \multicolumn{4}{|c|}{ 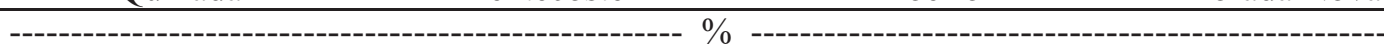 } \\
\hline Sempre verde & $87 \mathrm{a}$ & $97 \mathrm{a}$ & 89 abc & $90 \mathrm{a}$ \\
\hline Setentão & $84 \mathrm{a}$ & $92 \mathrm{a}$ & $94 \mathrm{a}$ & $82 \mathrm{ab}$ \\
\hline Patativa & $24 \mathrm{c}$ & $87 \mathrm{a}$ & $83 \mathrm{bc}$ & $65 \mathrm{c}$ \\
\hline Pingo de ouro & $92 \mathrm{a}$ & $90 \mathrm{a}$ & $90 \mathrm{ab}$ & $80 \mathrm{ab}$ \\
\hline Aparecido & $88 \mathrm{a}$ & $93 a$ & $85 \mathrm{bc}$ & $89 a$ \\
\hline Epace-10 & $70 \mathrm{~b}$ & $87 \mathrm{a}$ & $82 \mathrm{c}$ & $74 \mathrm{bc}$ \\
\hline CV (\%) & 7,76 & 5,28 & 3,84 & 7,51 \\
\hline
\end{tabular}

${ }^{1}$ As médias seguidas pela mesma letra, na coluna, não diferem entre si pelo teste de Tukey a 5\% de probabilidade de erro. 
Patativa, apesar desta constatação, a exceção da produzida em Quixadá (68\%), a emergência de plântulas, para a Patativa, foi superior a 90\% em Pentecoste, Limoeiro do Norte e Morada Nova. Sementes de baixo vigor determinaram redução, retardamento e desuniformidade na emergência no campo, na cultura de aveia preta, segundo Schuch et al. (1999) e sementes de vigor elevado produziram plântulas com maior tamanho inicial, o que proporcionou maiores taxas de crescimento no período inicial de crescimento da cultura. Resultado semelhante foi encontrado por Machado (2002), trabalhando com aveia branca. A Patativa não diferiu das outras cultivares quando a mesma foi produzida em Pentecoste e Limoeiro do Norte. Em Morada Nova, a Patativa não deferiu das cultivares Aparecido e Epace-10 (Tabela 3). Em trabalho com três cultivares de feijão, Jauer et al. (2002) verificaram diferença entre as cultivares através dos testes de emergência de plântulas e condutividade elétrica, sendo a cultivar IAPAR 44 a que apresentou menor vigor, dentre aquelas testadas, ou seja, a Xamego, a TPS Bionobre e a TPS Nobre.

Analisando os resultados obtidos no índice de velocidade de emergência (Tabela 4), verificou-se que não houve diferença entre as cultivares produzidas em Pentecoste. Nas outras localidades, a cultivar Patativa foi a que apresentou a menor qualidade, muito embora em determinadas situações, localidades, não ter diferido das cultivares Setentão, Epace10 e Sempre Verde. A diferença na qualidade fisiológica entre lotes de sementes de soja, podem ser atribuídas, não só ao genótipo, conforme afirmaram Panobianco e Vieira (1996), mas podem ser atribuídas, principalmente, aos efeitos das condições ambientais prevalecentes durante a fase de maturação e colheita, segundo Aguero et al. (1997).

Quando as sementes das cultivares estudadas foram submetidas ao teste de condutividade elétrica, a exemplo dos testes de vigor anteriormente analisados, a cultivar Patativa mais uma vez apresentou qualidade fisiológica inferior, quando comparada com as outras cultivares testadas, fato observado agora nas quatro localidades (Tabela 5). Em duas situações, Pentecoste e Morada Nova, a Patativa não diferiu das cultivares Pingo de Ouro e Sempre Verde, respectivamente. Os maiores valores de lixiviação de solutos corresponderam as menores porcentagens de plântulas normais como resultados deste teste. Resultados semelhantes foram

TABELA3. Resultados do teste de emergência de plântulas de seis cultivares de feijão caupi colhidas em quatro localidades do Estado do Ceará, Fortaleza, 2005.

\begin{tabular}{|c|c|c|c|c|}
\hline \multirow{3}{*}{ Cultivares } & \multicolumn{4}{|c|}{ Locais } \\
\hline & Quixadá & Pentecoste & Limoeiro & Morada Nova \\
\hline & \multicolumn{4}{|c|}{ } \\
\hline Sempre verde & $97 \mathrm{a}$ & $99 \mathrm{a}$ & 99 a & $99 \mathrm{a}$ \\
\hline Setentão & $94 \mathrm{a}$ & $99 \mathrm{a}$ & $97 \mathrm{a}$ & $99 \mathrm{a}$ \\
\hline Patativa & $68 \mathrm{~b}$ & $97 \mathrm{a}$ & $95 \mathrm{a}$ & $93 \mathrm{~b}$ \\
\hline Pingo de ouro & $99 \mathrm{a}$ & $99 \mathrm{a}$ & $96 a$ & $99 \mathrm{a}$ \\
\hline Aparecido & $97 \mathrm{a}$ & $98 \mathrm{a}$ & $95 \mathrm{a}$ & $98 \mathrm{ab}$ \\
\hline Epace-10 & $94 \mathrm{a}$ & $99 \mathrm{a}$ & $96 \mathrm{a}$ & $97 \mathrm{ab}$ \\
\hline CV (\%) & 4,30 & 2,27 & 2,33 & 2,58 \\
\hline
\end{tabular}

${ }^{1}$ As médias seguidas pela mesma letra, na coluna, não diferem entre si pelo teste de Tukey a 5\% de probabilidade de erro.

TABELA4. Resultados do teste índice de velocidade de emergência de seis cultivares de feijão caupi colhidas em quatro localidades do Estado do Ceará, Fortaleza, 2005².

\begin{tabular}{lcccc}
\hline & \multicolumn{4}{c}{ Locais } \\
\cline { 2 - 5 } Cultivares & Quixadá & Pentecoste & Limoeiro & Morada Nova \\
\hline Sempre verde & $15,37 \mathrm{a}$ & $15,51 \mathrm{a}$ & $14,42 \mathrm{a}$ & $14,67 \mathrm{ab}$ \\
\hline Setentão & $13,12 \mathrm{~b}$ & $15,38 \mathrm{a}$ & $12,57 \mathrm{~b}$ & $15,28 \mathrm{a}$ \\
Patativa & $9,22 \mathrm{c}$ & $15,02 \mathrm{a}$ & $13,36 \mathrm{ab}$ & $13,40 \mathrm{~b}$ \\
Pingo de ouro & $14,73 \mathrm{ab}$ & $15,56 \mathrm{a}$ & $15,00 \mathrm{a}$ & $15,49 \mathrm{a}$ \\
Aparecido & $15,04 \mathrm{a}$ & $15,81 \mathrm{a}$ & $14,96 \mathrm{a}$ & $15,97 \mathrm{a}$ \\
Epace-10 & $14,42 \mathrm{ab}$ & $15,40 \mathrm{a}$ & $14,21 \mathrm{ab}$ & $14,65 \mathrm{ab}$ \\
\hline CV $(\%)$ & 6,09 & 3,92 & 5,41 & 5,20 \\
\hline
\end{tabular}

${ }^{1}$ As médias seguidas pela mesma letra, na coluna, não diferem entre si pelo teste de Tukey a 5\% de probabilidade de erro. 
TABELA5. Resultados de condutividade elétrica de seis cultivares de feijão caupi colhidas em quatro localidades do Estado do Ceará, Fortaleza, 2005'.

\begin{tabular}{|c|c|c|c|c|}
\hline \multirow{3}{*}{ Cultivares } & \multicolumn{4}{|c|}{ Locais } \\
\hline & Quixadá & Pentecoste & Limoeiro & Morada Nova \\
\hline & \multicolumn{4}{|c|}{--------------------------------------------------- $\mu \mathrm{S} \mathrm{c} \mathrm{cm}$-------------------------------------------------- } \\
\hline Sempre verde & $62,49 \mathrm{bc}$ & $37,12 \mathrm{c}$ & $46,65 \mathrm{~b}$ & 79,92 a \\
\hline Setentão & $60,34 \mathrm{bc}$ & $40,66 \mathrm{bc}$ & $38,14 \mathrm{~cd}$ & $51,93 \mathrm{~b}$ \\
\hline Patativa & $149,00 \mathrm{a}$ & $62,33 \mathrm{a}$ & $65,51 \mathrm{a}$ & $86,71 \mathrm{a}$ \\
\hline Pingo de ouro & $75,27 \mathrm{~b}$ & $51,38 \mathrm{ab}$ & $46,10 \mathrm{~b}$ & $48,91 \mathrm{~b}$ \\
\hline Aparecido & $41,34 \mathrm{~d}$ & $37,69 \mathrm{c}$ & $43,68 \mathrm{bc}$ & $50,05 \mathrm{~b}$ \\
\hline Epace-10 & $51,75 \mathrm{~cd}$ & $31,97 \mathrm{c}$ & $36,94 \mathrm{~d}$ & $49,64 \mathrm{~b}$ \\
\hline $\mathrm{CV}(\%)$ & 10,87 & 11,85 & 6,21 & 6,36 \\
\hline
\end{tabular}

${ }^{1}$ As médias seguidas pela mesma letra, na coluna, não diferem entre si pelo teste de Tukey a 5\% de probabilidade de erro.

encontrados por Andrade et al. (1995) com sementes de cenoura e Peixoto et al. (1998) com sementes de milho. Trabalhando com dois lotes sementes de feijão, cultivar IAPAR 44, Santos et al. (2004) observaram através do teste de condutividade elétrica que no lote 1 , parece ter ocorrido maiores mudanças deteriorativas em relação ao lote 2 , que exibiu menor lixiviação, possivelmente, apresenta maior capacidade para reorganizar e reparar danos nas membranas, sendo, portanto, de qualidade superior.

De maneira geral, a cultivar Pingo de Ouro se adaptou melhor nos municípios de Quixadá e Morada Nova; a cultivar Sempre Verde em Pentecoste e Morada Nova; a Setentão em Limoeiro do Norte e a Aparecido somente no município de Morada Nova.

\section{CONCLUSÕES}

Para a maioria das cultivares testadas, as sementes produzidas nos municípios de Pentecoste e Limoeiro do Norte apresentaram qualidade fisiológica superior em comparação com àquelas produzidas nos municípios de Quixadá e Morada Nova;

As sementes das cultivares Sempre Verde, Setentão, Pingo de Ouro e Aparecido apresentaram desempenho fisiolõgico superior, as da Epace-10 desempenho intermediário e as da Patativa, desempenho inferior.

\section{REFERÊNCIAS}

AGUERO, J.A.P.; VIEIRA, R.D.; BITTENCOURT, S.R.M. Avaliação da qualidade fisiológica de sementes de cultivares de soja. Revista Brasileira de Sementes, Brasília, v.19, n.2, p.255260, 1997.
Ambrosano, E.J.; AMBRosANO, G.M.B.; WUTKE, E.B.; BULISANI, E.A.; MARTINS, A.L.M.; SILVEIRA, L.C.P. Efeitos da adubação nitrogenada e com micronutrientes na qualidade de sementes de feijoeiro cultivar IAC-Carioca. Bragantia, Campinas, v.58, n.2, p.393-399, 1999.

ANDRADE, R.N.; SANTOS, D.S.B.; SANTOS FILHO, B.G.; MELO, V.D.C. Correlação entre testes de vigor em sementes de cenoura armazenadas por diferentes períodos. Pesquisa Agropecuária Gaúcha, Porto Alegre, v.1, n.2, p.153-162, 1995.

BANZATTO, D.A.; KRONKA, S.N. Experimentação agrícola. 2. ed. Jaboticabal: FUNEP/UNESP, 1992. 247p.

BRAGANTINI, C. Produção de sementes. In: ARAUJO, R.S.; RAVA, C.A.; STONE, L.F.; ZIMMERMANN, M.J. (Eds.). Cultura do feijoeiro comum no Brasil. Piracicaba: POTAFOS, 1996, p.639667.

BRASIL, Ministério da Agricultura e da Reforma Agrária. Regras para análise de sementes. Brasília: SNAD/DNDV/CLAV, 1992. 365p.

COSTA, N.P.; MESQUITA, C.M.; MAURINA, A.C.; FRANÇANETO, J.B.; PEREIRA, J.E.; BORDINGNON, J.R.; KRZYZONOWSKI, F.C.; HENNING, A.A. Efeito da colheita mecânica da soja nas características físicas, fisiológicas e químicas das sementes em três estados brasileiros. Revista Brasileira de Sementes, Brasília, v.23, n.1, p.140-145, 2001.

DAMIÃO FILHO, C.F; MÔRO, F.V. Morfologia externa das espermatófitas. Jaboticabal: FUNEP, 2001. 101p.

KRZYZANOWSKI, F.C.; GILIOLI, J.L.; MIRANDA, L.C. Produção de sementes nos cerrados. In: ARANTES, N.E.; SOUZA, P.I.M. (Eds.). Cultura da soja nos cerrados. Piracicaba: Potafos, 1993, p.465-522.

JAUER, A.; MENEZES, N.L.; GARCIA, D.C. Tamanho de sementes na qualidade fisiológica de cultivares de feijoeiro comum. Revista da Faculdade de Zootecnia, Veterinária e Agronomia, Uruguaiana, v.9, n.1, p.121-127, 2002.

MACHADO, R.F. Desempenho de aveia branca (Avena sativa L.) em função do vigor de sementes e população de plantas. 2002. 46f. Dissertação (Mestrado em Ciência e Tecnologia de Sementes) Universidade Federal de Pelotas, Pelotas, 2002. 
MAGUIRE, J.D. Speed of germination-aid selection and evaluation for seedling emergence and vigor. Crop Science, Madison, v.2, p.176-177, 1962.

PANOBIANCO, M.; VIEIRA, R.D. Electrical conductivity of soybean seed. I - Effect of the genotype. Pesquisa Agropecuária Brasileira, Brasília, v.31, n.9, p.621-627, 1996.

PEIXOTO, A.R.; TORRES, S.B.; KARASAWA, M. Qualidade sanitária e fisiológica de sementes de milho produzidas no submédio São Francisco. Revista Brasileira de Sementes, Brasília, v.20, n.1, p.12-15, 1998.

SANTOS, C.M.R.; MENEZES, N.L.; VILLELA, F.A. Alterações fisiológicas e bioquímicas em sementes de feijão envelhecidas artificialmente. Revista Brasileira de Sementes, Brasília, v.26, n.1, p.110-119, 2004.

SANTOS, M.R.; REIS, M.S.; SEDIYAMA, T.; CECON, P.R.; DIAS, D.C.F.S. Qualidade fisiológica e sanitária de sementes de genótipos de soja colhidas em três regiões de Minas Gerais. Revista
Brasileira de Sementes, Brasília, v.22, n.2, p.62-71, 2000.

SCHUCH, L.O.B.; NEDEL, J.L.; ASSIS, F.N.; MAIA, M.S. Crescimento em laboratório de plântulas de aveia preta (Avena strigosa Schreb) em função do vigor das sementes. Revista Brasileira de Sementes, Brasília, v.21, n.1, p.229-235, 1999.

SOUZA, A.A.de; BRUNO, R.L.A.; ARAÚJO, E.; MEDEIROS FILHO, S.; COSTA, R.F.da. Influência do horário de colheita na qualidade de sementes do algodoeiro produzidas em três microrregiões do Estado da Paraíba. Revista Brasileira de Sementes, Brasília, v.26, n.1, p.1-8, 2004.

VIEIRA, R.F.; VIEIRA, C.; RAMOS, J.A.O. Produção de sementes de feijão. Viçosa: EPAMIG/EMBRAPA, 1993. 131p.

YOKOYAMA, L.P.; WETZEL, C.T.; VIEIRA, E.H.N.; PEREIRA, G.V. Sementes de feijão: produção, uso e comercialização. In: VIEIRA, E.H.N.; RAVA, C.A. (Eds.). Sementes de feijão: produção e tecnologia. Santo Antônio de Goiás: EMBRAPA, 2000, p.249270. 